\title{
Important interrelations between posturology, vestibular disorders and dentistry
}

\author{
M. Milkov', M. Stoykov', H. Arnautska', S. Peev' ${ }^{1}$ D. Petrova ${ }^{2}$ \\ ${ }^{1}$ Faculty of Dental Medicine, Medical University - Varna \\ ${ }^{2}$ Medical University - Varna
}

\begin{abstract}
Human posture is defined as any position that determines the balance with maximum stability, minimum energy consumption and minimum stress on the anatomical structures. Research done on posture makes authors look at the postural system as a whole. The aim of this article is to preview the connections between dentistry, postural science and vestibulogy.

Scientific databases - Scopus, MEDLINE, PubMed were used for the research, with the following keywords - posturology, vertigo, dental medicine, orthodontics, pathological bite, for the 2000-2020time period. Apart from scientific articles, information from different symposiums and lectures was included. The target was to briefly point out and summarize the most important relations between the topics.

Posture is controlled by the central nervous system (CNS), leading to postural corrections. They are the result of a complex system of mechanisms, controlled by multisensory CNS-integrated inputs. The fine postural system (FPS) aims to maintain balance in the most economical way possible. Stomatognathic system is another functional unit, connected to postural system. The science that studies human posture is called posturology and is a part of integrative medicine. Integrative clinical posturology is a complex, multidisciplinary science that uses various investigation methods in several stages: detailed anamnesis; An in-depth posturological examination - including measurements and tests - for vestibular and visual function and stabilometry.

In conclusion, it can be said that posturology is a modern and, at the same time, an ancient constantly evolving, interdisciplinary, "borderline" science. It unites different specialists and helps to build an individual approach to each patient, providing a higher quality of life. There is a connection between vestibular disorders, posturological science and dentistry. Through the methods of the science for posture, occurring disorders can be detected at a much earlier stage and appearance of severe pathology prevented.

Key words: posturology, vestibular disorders, vertigo, dental medicine, orthodontics, pathological bite
\end{abstract}

\section{Introduction}

Human posture aims to keep the body in balance when performing dynamic movements or in a static position. Research done on the posture for more than a hundred years makes authors look at the postural system as a whole and some of its additional functions such as: fighting gravity to stay upright, opposition to external forces, finding exact place in the surrounding space, maintaining balance while moving. (1) Therefore, posture is defined as any position that determines the balance with maximum stability, minimum energy consumption and minimum stress on the anatomical structures. (2), (3)

The aim of this article is to preview the connections between dentistry, postural science and vestibulogy. Long ago those connections were proven, but still - scientists lead disputes about the correlations between the specified fields of medical knowledge and the need for interdisciplinary care for the patient.

\section{Material and methods}

Scientific databases - Scopus, MEDLINE, PubMed were used for the research, with the following keywords - posturology, vertigo, dental medicine, orthodontics, pathological bite, for the 20002020-time period. Apart from scientific articles, information from different symposiums and lectures 
was included. The target was to briefly point out and summarize the most important relations between posturology, dentistry and vestibular sciences.

\section{Discussion}

Posture involves muscle activation that is controlled by the central nervous system (CNS), leading to postural corrections. (4) Postural corrections are the result of a complex system of mechanisms with multisensory inputs (visual, vestibular, and somatosensory) integrated into the CNS. (5) These corrections are caused by several types of afferent inputs: exteroceptive (sensitivity of the skin of the feet - they often act as a buffer), proprioceptive (receptors located in the skin, muscles, tendons, ligaments and joints), vestibular (utriculus, sacculus, semicircular canals), visual (retina). These afferent inputs can be modulated by a number of factors such as mood and anxiety. (6)

The fine postural system (FPS) also plays an important role in maintaining posture. It aims to maintain balance in the most economical way possible. People suffering from a FPS disorder have clinical manifestations such as: occlusal problems, pathology of the temporomandibular joint and masticatory muscles, orthodontic deformities, pain in the neck, back and lower back, problems with balance, dizziness, muscle fatigue, difficulty maintaining certain postures, visual disturbances, muscle imbalance and dysfunction, changes in feet and gait, etc. (7)

Stomatognathic system plays a significant role in postural control as well. It is a functional unit consisting of: skeletal components (upper and lower jaw), dental arches, soft tissues (salivary glands, nerves and vessels), temporomandibular joint and masticatory muscles. All work in harmony to perform different functional tasks. (5)

Correct posture is an important part of long-term health and affects the whole body. When the body's posture during static and dynamic activities is correct, pain, injuries, vestibular and other health problems can be prevented. (8), (15)

The science that studies human posture is called posturology. It deals with the diagnosis, dynamic monitoring and studying of various disorders of the balance function. It formed as an independent branch in the late $60 \mathrm{~s}$ of $20^{\text {th }}$ century, when the International Posturological Society was established. (9) Postural science has been actively developing all over the world in the last 50 years. In the last three years a rise in its development has been observed in our country as well. At the beginning of 2018, the Bulgarian Association of Posturology (BAP) was founded with the aim to develop and promote the science of the correct posture in Bulgaria and the Balkan peninsula. (7)

The science of posturology is part of integrative medicine. Integrative clinical posturology is a complex, multidisciplinary science that brings togetheralargenumberofmedicalprofessionals, such as dentists, otoneurologists, otorhinolaryngologists, ophthalmologists, neurologists, pediatricians, rehabilitators and many others, depending on the case. Posturology considers the human body as a single complete system in which everything is interconnected. Emphasis is placed on the individual characteristics of the patient. Posturology provides clinicians with a set of knowledge and observation techniques through which valuable information can be obtained, concerning the overall health condition of their patients. One of the examples for proving the connection between the separate structures of the organism is the so-called "Postural deficit syndrome", largely associated with the maxillofacial system. It is proven that a pathologically altered bite can change a person's posture. Impaired posture can manifest in many different ways: problems with maintaining balance (dizziness, vertigo, etc.), all associated with the vestibular system, disturbed balance and increased risk of falling, muscle fatigue, difficulty maintaining certain positions and performing movements, postural changes, plantar modifications, occlusal changes or dysfunction of the temporomandibular joint, eye and oculomotor problems, visceral problems, changes in emotion, stress and anxiety, pain in the neck, shoulders and back, scoliosis, etc. For example, due to foot problems, there may be problems with the mandibular joint and vice versa. Pain in the lower back, neck and knees can occur due to problems with missing teeth. Eye problems and incorrectly made glasses lead to a change in posture and not only in the vision. (8), (10) Dental abnormalities associated with impaired bite can lead to postural disturbances, and impaired posture may cause vestibulopathy. Indirect evidence suggests a functional link between the vestibular and trigeminal systems. For example, painful trigeminal stimulation can cause or modulate auditory and vestibular symptoms, such as spontaneous nystagmus, in patients with migraine headaches. (11), (12) These disorders can 
be overcome by an adequate treatment, selected individually according to each clinical case. It can be concluded that there is a clear connection between all organs and systems in the human body. The study of posture helps clinicians understand the condition of the whole human body, analyze the information obtained, draw appropriate conclusions for a particular patient based on individual characteristics and decide which of the specialists to start treatment first or how the therapy itself will take place. In this way, the patient derives maximum benefit from the treatment by acting not only on the organ or system affected by the specific disease, but also a beneficial effect on general health and the whole organism is visible. When the study of structure does not help, function is important. Integrated clinical posturology helps to find the answer. In fact, it is another diagnostic and treatment method that allows for a complete assessment of the human body and health through posturological examination. (10) Postural analysis takes place in several stages:

1) Analysis of the whole - detailed anamnesis, a standardized form should be filled out with questions related to the specific complaints of the patient, past illnesses, relevant to the diagnosis.

2) An in-depth examination is then performed, the difference between a standard medical examination and a posturological examination being that latter lasts about an hour and a half, including various measurements and tests (dynamic and static), tests for vestibular and visual function allowing assessment of the patient's posture and overall vestibular and visual health.

3) Finally, it is investigated to what extent the hypotheses regarding the diagnosis can be confirmed by certain influences that reject or confirm it and then it is determined which specialist should start the treatment in the given patient first. (10)

One of the ways to perform posturological examination is through stabilometric platforms. These are devices that allow the registration of the projection of the common center of mass of the body of the patient standing on the platform and its movement in time. This method is also called stabilometry. Stabilometric research has been used since 1983, and today it is undergoing significant development and improvement. (13), (14) Stabilometric platforms can be used to study balance and different reactions of the balance management systems. That allows a completely different approach to relatively known diseases, as well as to discover new features of the functions of the proprioceptive, neuromuscular, visual, vestibular and other systems. (9)

\section{Conclusion}

In conclusion, it can be said that posturology science for posture - is a modern and, at the same time, an ancient science, constantly evolving and becoming increasingly popular in Bulgaria as well. Posturology is an interdisciplinary, "borderline" science which unites different specialists and helps to build an individual approach to each patient, providing a higher quality of life to patients. The human body is considered as a whole and not as a separate organ or system. That is certainly beneficial for human health. There is a connection between vestibular disorders, posturological science and dentistry. Through the methods of the science for posture, occurring disorders can be detected at a much earlier stage and appearance of severe pathology prevented.

The presented article was a part of the $14^{\text {th }}$ National congress of otorhinolaryngology - quality in the otorhinolaryngology, despite the routine, 2021.11.2020 - virtual presentation on 20.11.2020 18:55.

\footnotetext{
References:

1. Carini F, Mazzola M, Fici C, Palmeri S, Messina M, Damiani P, Tomasello G. Posture and posturology, anatomical and physiological profiles: overview and current state of art. Acta Biomed. 2017 Apr 28;88(1):11-16. doi: 10.23750/abm.v88i1.5309. PMID: 28467328; PMCID: PMC6166197.

2. Barker V. Postura, Posizione e Movimento. Ed. Mediterranee. 1998

3. Pastorelli F, Pasquetti P. Biomechanical analysis and rehabilitation in athletes. Clin Cases Miner Bone Metab. 2013;10(2):96.

4. Kandel ER, Schwartz JH, Jessell TM. Principles of Neural Science. 3rd ed. New York: Elsevier Science Publication Co; 1991.

5. Cuccia A, Caradonna C. The relationship between the stomatognathic system and body posture. Clinics (Sao Paulo). 2009;64(1):61-66.
} 
doi:10.1590/s1807-59322009000100011

6. Bolmont B, Gangloff P, Vouriot A, Perrin Ph. Mood states and anxiety influence abilities to maintain balance control in healthy human subjects. Neurosci Lett. 2002;329:96-100.

7. Какво е постурология? Конференция по интегративна медицина и постурология: 7 декември 2019, София, България

8. Physioworks Posture Correction Available from: https://physioworks.com.au/treatments-1/posture-correction

9. Постурология - новата парадигма в интегративната медицина - в света съществува от 50 години, а в България е неизвестна. - Д-р Венцислав Стоев

10. Постурологията - новата парадигма в медицината. Лекция д-р Венцислав Стоев, III Научен Конгрес ,Наука и практика - ръка за рька‘ - 30.10-01.11.2020г., гр. Пловдив, България, организиран с подкрепата на Българския зъболекарски съюз, РК-Пловдив и ФДМ-Пловдив.

11. Marano E, Marcelli V, Di Stasio E, Bonuso S, Vacca G, Manganelli F, et al. Trigeminal Stimulation Elicits a Peripheral Vestibular Imbalance in Migraine Patients. Headache. 2005;45:325-31.

12. Vass Z, Shore SE, Nuttall AL, Miller JM. Direct evidence of trigeminal innervation of the cochlear blood vessels. Neuroscience. 1998;84:55967.

13. Bizzo G., Guillet M., Patat A. et al. Specifications for building a vertical force platform designed for clinical stabilometry. Med. \& Biol. Eng. \& Comput., 1985.- N23.- p.474-476.

14. Kapteyn T.S., Bles W., Njiokiktjien Ch.J. et al. Standartization in platform stabilometry being a part of posturography. Agressologie, 1983.N24, Vol.7.- p.321-326.

15. Widhe T. Spine: posture, mobility and pain. A longitudinal study from childhood to adolescence. European Spine Journal. 2001 Apr $1 ; 10(2): 118-23$ 